\title{
Configurações
}

Revista de sociologia

\section{Ensino Superior e inserção profissional - uma análise comparativa de percursos de licenciados}

Higher Education and Transition to Working Life: a comparative analysis of graduates' trajectories

L'enseignement supérieur et insertion professionnelle : analyse comparative des trajectoires des diplômés

\section{Mariana Gaio Alves}

\section{(2) OpenEdition}

\section{Journals}

Edição electrónica

URL: http://journals.openedition.org/configuracoes/175

DOI: 10.4000/configuracoes. 175

ISSN: 2182-7419

\section{Editora}

Centro de Investigação em Ciências Sociais

\section{Edição impressa}

Data de publição: 30 Junho 2010

Paginação: 47-64

ISSN: 1646-5075

\section{Refêrencia eletrónica}

Mariana Gaio Alves, « Ensino Superior e inserção profissional - uma análise comparativa de percursos de licenciados ", Configurações [Online], 7 | 2010, posto online no dia 18 fevereiro 2012, consultado o 19 abril 2019. URL : http://journals.openedition.org/configuracoes/175; DOI : 10.4000/ configuracoes. 175

Este documento foi criado de forma automática no dia 19 Abril 2019. 


\title{
Ensino Superior e inserção profissional - uma análise comparat iva de percursos de licenciados
}

\author{
Higher Education and Transition to Working Life: a comparative analysis of \\ graduates' trajectories \\ L'enseignement supérieur et insertion professionnelle : analyse comparative des \\ trajectoires des diplômés
}

Mariana Gaio Alves

\section{Notas introdutórias}

1 Este artigo pretende contribuir para o debate do tema "trabalho" e "não trabalho" nas sociedades contemporâneas, reportando alguns dados resultantes de estudos sobre a inserção profissional de diplomados do Ensino Superior realizados em instituições deste nível de ensino. O conhecimento sobre a inserção profissional destes revela-se particularmente importante na contemporaneidade, pois, se na sociedade pré-industrial o trabalhador típico é o trabalhador manual com recurso a algumas ferramentas e instrumentos e na sociedade industrial o trabalhador típico é o trabalhador manual da fábrica, aponta-se, na actualidade, que o trabalhador típico é o que se baseia no conhecimento. O aumento dos níveis médios de escolaridade da população, em paralelo com a terciarização das economias, tem vindo a resultar num crescimento dos profi ssionais técnicos e científicos com diplomas de Ensino Superior, surgindo o debate em torno das implicações destas tendências gerais nas características dos percursos de inserção profi ssional deste grupo populacional.

2 Em Portugal, como em muitos outros países, o tema da transição entre Ensino Superior e mercado de trabalho tem tido grande visibilidade social nos últimos anos, sendo alvo de preocupação e debate quer por parte da sociedade em geral, quer no interior das instituições universitárias e politécnicas. O debate social em torno da situação profi 
ssional dos diplomados do Ensino Superior tende a enfatizar as dificuldades no acesso ao emprego que os mesmos vêm protagonizando, tornando urgente a consideração de resultados de investigação que permitam caracterizar com rigor os respectivos percursos e as situações de "trabalho" e "não trabalho".

3 Assim sendo, neste artigo recorre-se a resultados de uma análise comparativa de alguns estudos realizados em diversas instituições de Ensino Superior portuguesas (universidades e politécnicos), a qual tem o duplo objectivo de contribuir para o aprofundamento do conhecimento sobre estes processos de transição e de sistematizar aspectos inerentes à recolha e análise de informação sobre estas matérias. Num domínio em que a ausência de dados estatísticos a nível nacional não permite com rigor dispor de informação sobre a inserção profissional dos diplomados do Ensino Superior, o trabalho de análise comparativa realizado procura reunir dados que contribuam para aprofundar algumas interrogações que têm vindo a ser colocadas neste campo de investigação.

4 Neste artigo procura-se, inicialmente, contextualizar a análise comparativa realizada, para em seguida apresentar resultados da análise, quer no que respeita à situação profi ssional dos diplomados no momento da inquirição, quer em termos das suas opiniões relativas à situação profissional e à articulação entre Ensino Superior e profissão. No final, sistematizam-se alguns resultados substantivos da análise comparativa e, adicionalmente, evidenciam-se as difi culdades do exercício realizado.

\section{Contextualização teórica e metodológica da análise comparativa}

5 Na investigação que desenvolvemos sobre estas matérias, temos argumentado que é necessário considerar os processos de inserção profissional de diplomados como o resultado do confronto e da interacção entre um conjunto de actores com diferentes lógicas, estratégias e posicionamentos, não podendo de modo algum considerar-se a inserção profissional como uma consequência directa e exclusiva da acção do Ensino Superior (Alves, M., 2005, 2007). Aliás, em nosso entender, o estudo dos processos de inserção profissional não dispensa a consideração de pelo menos três unidades de análise - os empregadores, os académicos e os próprios diplomados - e das interacções entre eles, bem como implica ter em atenção as tendências estruturais de evolução socioeconómica e profi ssional e ainda os contextos locais e regionais que afectam aquelas três unidades de análise. Como sublinhamos num texto anterior, trata-se de considerar a articulação entre educação, trabalho e emprego sob a forma de uma "regulação", ou seja, enquanto modo de coordenação através do qual se produzem as normas e regras da interaç̧ão entre todos, sendo que este modo de coordenação não decorre de uma finalidade claramente de finida nem é controlado por nenhuma autoridade externa (Alves, M., 2008).

6 Tendo em conta estes pressupostos na análise das transições protagonizadas pelos diplomados entre Ensino Superior e mundo do trabalho, este artigo decorre da análise comparativa de alguns estudos realizados sobre esta matéria. Procura-se, por um lado, identificar traços convergentes e divergentes relativamente aos percursos de transição para a vida activa de diplomados do Ensino Superior revelados pelos diversos estudos nas várias instituições. Por outro lado, enunciam-se algumas refl exões sobre aspectos metodológicos dos estudos em análise, quer no que respeita aos instrumentos e 
estratégias de recolha de dados, quer no que se refere aos indicadores mobilizados nesses estudos.

$7 \mathrm{Na}$ análise comparativa optámos por considerar estudos realizados por instituições de Ensino Superior (universitárias ou politécnicas), tendo vindo a constatar-se a existência de um trabalho da responsabilidade da Fundação da Juventude que abrange três instituições de Ensino Superior algarvias que foi também considerado. Deste modo, foram analisados estudos que têm como ambição caracterizar a situação do conjunto de diplomados de uma diversidade de áreas disciplinares, excluindo-se estudos centrados apenas em alguns cursos ou áreas de formação que também têm sido realizados em várias instituições. Assim, ficaram excluídos da análise comparativa, por exemplo, os trabalhos realizados por Sebastião et al. (2009), Chaves e Morais (2008) ou Almeida et al. (2007) que incidem apenas sobre cursos de uma dada instituição de Ensino Superior, respectivamente, na área da Educação, das Ciências Sociais e Humanas e das Ciências Empresariais.

Este critério de selecção de estudos a comparar justifica-se pelo facto de se procurar considerar aqueles que permitem caracterizar a situação de um conjunto de diplomados diverso do ponto de vista das áreas disciplinares de formação mas uniforme no que respeita à(s) instituição(ões) de formação. Sabemos que, em alguns casos, estes trabalhos constituem a base de explorações mais aprofundadas que conduzem, designadamente, à realização de dissertações de doutoramento ${ }^{1}$ Para além disto, existem trabalhos de investigação de doutoramento que analisam os casos concretos de um ou mais cursos, áreas de formação e escolas/faculdades, mas optámos por não considerar estes estudos na nossa análise comparativa: por exemplo, Marques (2006), M. Alves, (2007) ou Chaves, (2010). Neste artigo procuram-se comparar estudos realizados com a ambição de abranger amostras representativas de diplomados de instituições, cuja oferta formativa recobre uma diversidade de áreas disciplinares.

9 Um outro critério adoptado na selecção dos estudos a considerar é o de que os que são objecto de análise comparativa correspondam a operações de recolha de dados concretizadas desde 2001 e que optaram pela inquirição conjunta de diplomados que terminaram, não num único momento, mas sim em vários anos lectivos. Trata-se de "inquéritos de percurso" que permitem reconstruir as trajectórias dos sujeitos num determinado lapso temporal. Deste modo, analisa-se a situação de diplomados do Ensino Superior numa perspectiva temporal relativamente alargada, considerando aqueles que vêm concluindo os seus cursos desde meados dos anos 90 . Ou seja, procurou-se considerar estudos que se reportem a períodos cronológicos não muito distantes e, portanto, não muito diversos no que respeita à conjuntura económica e, ainda, estudos que opta-ram, de modo semelhante, por inquéritos que permitem retratar o percurso dos inquiridos durante três a cinco anos após a conclusão dos cursos.

10 Não obstante, sabemos que em algumas instituições (por exemplo na Universidade do Porto) têm vindo a ser realizados inquéritos aos diplomados do ano lectivo anterior (trata-se de "inquéritos de inserção"), o que constitui uma prática que provavelmente se tornará mais habitual nas instituições de Ensino Superior, tendo em conta a imposição de que estas disponham desses dados no quadro dos processos de avaliação a que são sujeitas pela respectiva tutela ${ }^{2}$.

11 Para além disto, também estamos cientes de que em algumas instituições (por exemplo nas Universidades de Aveiro e de Lisboa) os estudos que analisámos foram precedidos de outras iniciativas semelhantes, pelo que permitem dar indícios sobre a evolução da 
inserção profissional de diplomados daquelas instituições em tempos distintos. Evidentemente, o conjunto de estudos que foram objecto de análise comparada é constituído por aqueles que nos foi possível, de momento, identificar e a cujos relatórios finais tivemos acesso, não sendo de ignorar que outros existem ${ }^{3}$.

Assim, na sequência dos critérios aplicados, neste texto procura dar-se conta da análise comparativa do seguinte conjunto de estudos:

- Trajectórias académicas e de inserção profissional dos Licenciados 1999-2003, da Universidade de Lisboa, publicado em 2005;

- Percursos de inserção profissional dos diplomados do Ensino Superior Politécnico do Instituto Politécnico de Beja, publicado em 2005;

- A inserção profissional dos jovens diplomados no Algarve entre 1999 e 2001 da Delegação do Algarve da Fundação da Juventude publicado em 2004';

- Sistemas de (des)emprego: trajectórias de inserção da Universidade de Aveiro, publicado em 2002.

\section{Caracterização geral dos estudos numa perspectiva comparada}

Escolhemos realizar uma análise comparativa que permita situar os estudos realizados do ponto de vista cronológico e institucional, mas também no que respeita às metodologias de trabalho empírico concretizadas. Sobre esta matéria (ver o quadro $1 \mathrm{em}$ anexo) importa destacar que, do ponto de vista da metodologia do trabalho empírico, os estudos das Universidades de Lisboa e de Aveiro se distinguem dos que foram realizados no Instituto Politécnico de Beja e no Algarve.

Com efeito, os dois primeiros assentam na aplicação de um inquérito por questionário e no respectivo tratamento de dados, revelando a intencionalidade de, essencialmente, descrever as trajectórias de inserção dos diplomados daquelas duas universidades. Refirase, a título ilustrativo, que no caso do estudo referente à Universidade de Aveiro se afirma a dado momento que "os dados serão apresentados de forma descritiva, não se procurando fazer a sua interpretação à luz de qualquer teoria" (Martins, Arroteia e Gonçalves, 2002, p. 21). Note-se que ambos os estudos correspondem a uma segunda edição deste tipo de trabalho e estão na base de dissertações de doutoramento de um dos autores, nas quais se exploram e complementam os dados referentes àquelas instituições universitárias (Gonçalves, 2007, Alves; N. 2008).

Por seu turno, os estudos concretizados em Beja e no Algarve foram fi nanciados no quadro de um mesmo programa operacional e incluem mais do que uma única fase de trabalho empírico, combinando a informação em extensividade junto dos diplomados com a realização de entrevistas a grupos restritos de informantes privilegiados e/ou diplomados. Acresce, ainda, que ambas as publicações não se limitam a apresentar os dados empíricos recolhidos, mas procuram enquadrá-los do ponto de vista teórico e conceptual.

Um traço característico comum aos quatro estudos é o facto de se centra-rem, exclusivamente, na análise de diplomados que concluíram uma formação inicial de nível superior, não abrangendo o estudo de trajectórias profi ssionais e educativas de diplomados de pós-graduação. Noutros países, o crescimento acentuado dos diplomados de nível pós-licenciatura, mais precocemente do que em Portugal, já originaram trabalhos 
de pesquisa e caracterização dos percursos profissionais e educativos de pós-graduados, mestres e doutores antes e depois do regresso ao Ensino Superior (ver, a título ilustrativo, Dubois, 2004). No caso português, não conhecemos dados sistemáticos sobre os percursos de mestres e doutores recolhidos pelas instituições de Ensino Superior, mas em projecto de investigação anterior procurámos, num grupo restrito de cursos e instituições, estudar as trajectórias educativas e profissionais de mestres e doutores (Alves, M., 2008) e sabemos que outras pesquisas estão em curso neste domínio.

Nos estudos que estamos a analisar, todos os questionários foram aplicados por via postal, sendo de destacar que, em geral, os diplomados aderem em número assinalável a estas iniciativas, obtendo-se taxas de resposta expectáveis para uma inquirição por esta via: no estudo da Universidade de Lisboa refere-se uma taxa de retorno próxima dos 30\% (Alves, N., 2005, p. 11), a mesma taxa é de $35,3 \%$ no caso da Universidade de Aveiro (Martins, Arroteia e Gonçalves, 2002, p. 13), de 26,9\% no trabalho sobre o Instituto Politécnico de Beja (Saúde, 2005, p. 17) e no caso do Algarve (único estudo em que não foram as instituições de Ensino Superior a coordenar o trabalho) a taxa de resposta, ligeiramente mais baixa, situa-se nos $23 \%$ (Geraldes et al., 2004, p. 179).

Adicionalmente, identifica-se em todos os estudos considerados uma tendência ligeira para serem os diplomados que há menos tempo se diplomaram a responderem em maior número. A observação das taxas de resposta obtidas nos inquéritos recentemente realizados na Universidade do Porto confi rma esta mesma tendência, pois, ao inquirir diplomados que terminaram os estudos há apenas um ano, veriica-se que metade responde aos questionários (Gonçalves e Menezes, 2010).

Tal tendência pode ser interpretada de várias formas. Na verdade, pode ser o resultado da (ainda) maior proximidade à instituição que frequentaram que os induz a responder, mas pode também suceder que se trate de um efeito da menor probabilidade de ter ocorrido entretanto uma mudança de residência que dificulte a recepção dos questionários pelos diplomados. Para além disto, pode tratar-se da expressão de uma tendência que identifi cámos anteriormente para responderem em maior número aqueles que enfrentam maiores difi culdades na inserção profissional (Alves, M., 2007) e que se encontram, previsivelmente, mais representados entre os diplomados mais recentes.

20 Relativamente à constituição das amostras de respondentes, importa ressalvar que se identifica uma diversidade de procedimentos seguidos e operacionalizados nos quatro estudos. Verifica-se, nos casos das Universidades de Aveiro e de Lisboa e do Politécnico de Beja, a opção de enviar os questionários a todos os diplomados, controlando através de algumas variáveis até que ponto a amostra assim constituída apresenta enviesamentos e (des)respeita as proporções no universo do estudo de diferentes grupos. Essas variávies diferenciadoras dos grupos são o curso e o ano de conclusão do mesmo nos três estudos, assim como também o sexo (em Aveiro e Lisboa) e a média de licenciatura (apenas no caso de Lisboa). Relativamente ao estudo realizado na região algarvia, escolheu-se constituir uma amostra aleatória estratificada, estabelecendo estratos em função do ano de conclusão e estabelecimento de ensino frequentado.

21 No que respeita à apresentação de dados dos inquéritos por questionário realizados em cada um dos estudos, constata-se (ver Quadro 2 em anexo) que a forma de organização dos dados empíricos recolhidos é contrastante: em três deles inicia-se com a caracterização sociodemográfica ou sociográfica dos diplomados inquiridos, mas no outro (Algarve) tal secção é remetida para o fi nal da apresentação de dados; em dois casos (Universidade de Aveiro e Politécnico de Beja) a apresentação de dados parece tender a 
seguir a lógica cronológica de desenvolvimento dos percursos, referindo-se primeiro os elementos que se relacionam com o percurso académico e só depois os elementos caracterizadores do percurso e situação profi ssional actual, incluindo no fi nal as representações e opiniões dos inquiridos; enquanto nos restantes todas essas vertentes aparecem de forma mais mesclada (Universidade de Lisboa) ou essa lógica cronológica não é tão evidente (Algarve).

Apesar destas lógicas diferenciadas na estruturação da apresentação de dados, podemos identificar, do ponto de vista analítico, quatro dimensões de análise dos percursos dos diplomados que têm implícita uma lógica cronológica sequencial: caracterização sociográ fica dos inquiridos, caracterização dos percursos escolares no Ensino Superior, caracterização dos percursos de transição entre o Ensino Superior e o mundo do trabalho e caracterização da situação profi ssional no momento da inquirição.

Percebe-se, de modo claro, que o destaque conferido a cada uma destas dimensões de análise é diferente em cada um dos estudos, tendo em conta o número de indicadores mobilizados e, portanto, em termos da diversidade e profundidade da informação recolhida. Para além disto, é também notório que a informação analisada no quadro de cada uma daquelas quatro dimensões de análise contempla quer a recolha de dados que podem ser considerados de caracterização objectiva dos diplomados e dos seus percursos, quer a recolha de dados que remetem para as apreciações, opiniões e representações subjectivas dos diplomados relativamente aos seus percursos académico e profissional e à articulação/transição entre curso de Ensino Superior e mundo do trabalho.

Assim sendo, face à abrangência dos elementos de caracterização recolhidos nos quatro estudos em análise, optámos por, numa primeira aproximação, abordar a dimensão de análise que corresponde à "situação profissional no momento da inquirição", considerando uma caracterização objectiva dessa situação e uma dimensão objectiva relativa aos graus de satisfação com a profissão e com o modo como esta se adequa ao diploma. Considerámos que esta informação poderia revelar-se útil para discutir as dinâmicas de "trabalho" e "não trabalho" dos diplomados do Ensino Superior. A identifi cação dos indicadores em cada um dos quatro estudos que contribuem para esta dimensão de análise (a este propósito pode consultar-se o Quadro $3 \mathrm{em}$ anexo) revelou que apenas um grupo restrito é comum aos vários trabalhos e permite, com rigor, a comparabilidade dos dados obtidos nessas quatro operações de recolha de dados.

\section{A situação profissional no momento da inquirição numa perspectiva comparada}

Um dos aspectos mais enfatizados nos debates sociais sobre inserção profissional dos diplomados corresponde às taxas de emprego/desemprego deste grupo populacional. Se os dados estatísticos a nível europeu indicam que são os diplomados do Ensino Superior que protagonizam trajectórias menos marcadas pelo desemprego (Stiwen e Alves, 2010), a análise comparativa dos dados destes quatro estudos aponta nesse mesmo sentido.

Com efeito, constata-se que a grande maioria dos diplomados está empregada (70\% em Aveiro, $80 \%$ em Beja, $82 \%$ no Algarve, 77,5\% em Lisboa) e uma minoria desempregada (7,4\% em Aveiro, 15,2\% em Beja, 15,5\% no Algarve ${ }^{5}, 15,5 \%$ em Lisboa) no momento da inquirição. Para os estudos das Universidades de Aveiro e de Lisboa, acresce a estes números o grupo dos estagiários (com e sem remuneração) que representam $8,7 \%$ no 
primeiro caso e 5,5\% no segundo, não existindo esta informação nos outros dois estudos. Também com base nestes dois estudos é possível comparar a situação actual dos diplomados destas instituições com a verificada cerca de cinco anos antes, destacando-se que diminui o número e proporção de inquiridos empregados no momento da resposta ao questionário, o que parece traduzir a existência de maiores difi culdades no acesso ao emprego.

Adicionalmente, todos os estudos considerados evidenciam as variações dos valores globais de emprego/desemprego em função das áreas disciplinares dos cursos concluídos, do sexo dos indivíduos e do ano de conclusão do curso. No caso do Algarve a área das Ciências Exactas e Naturais é identifi cada como a mais "problemática" (Geraldes, 2004, p. 93), no sentido em que menos diplomados trabalham, enquanto nos estudos de Aveiro, Lisboa e Beja se regista uma convergência no sentido de nos cursos que dão acesso ao ensino em diferentes disciplinas se registarem dificuldades muito significativas e crescentes de acesso ao emprego. A este propósito, no caso do estudo da Universidade de Lisboa refere-se que o facto de a inquirição ter tido lugar em Outubro de 2004 (início de um ano lectivo no qual o concurso nacional de colocação de professores registou diversos atrasos e dificuldades) terá contribuído, em particular, para o resultado obtido no que respeita aos cursos vocacionados para a formação de professores (Alves, N., 2005).

No plano da diferenciação de género, sublinhe-se que são os indivíduos do sexo masculino que se encontram mais representados entre os empregados, como se refere nos estudos de Aveiro, Lisboa e Beja. Sobre o ano de conclusão, os quatros estudos concluem que o conjunto dos diplomados sem emprego engloba mais indivíduos que concluíram os cursos em anos mais recentes, o que está de acordo com o que anteriormente referimos relativamente à existência de uma associação entre mais tempo passado desde a conclusão do curso e menos difi culdades no mercado de trabalho.

Importa referenciar que, neste conjunto de estudos, a relação entre nota média final de curso e situação face ao emprego no momento da inquirição permanece um terreno pouco claro, pois no caso do Algrave embora se indique a inexistência de uma relação estatística entre essas duas variáveis também se refere que a "proporção de diplomados à procura de emprego é superior entre os diplomados com média mais baixa" (Geraldes, 2004, p. 94). Contudo, no caso de Aveiro afirma-se que tendem a estar empregados em maior número aqueles que terminaram com as notas mais baixas, realçando-se que aqueles que terminam com 16 ou mais se encontram como estudantes a tempo inteiro com bolsa.

Neste domínio, concluímos em pesquisa anterior (Alves, M., 2007) que não é possível estabelecer uma relação directa entre "sucesso escolar" e "sucesso na inserção profi ssional", tendo-se tornado notório que os alunos que exercem uma actividade profissional durante a licenciatura (maioritariamente rapazes) são, regra geral, os que demoram mais tempo a concluir os seus cursos, obtendo médias finais menos elevadas. Não obstante, estes mesmos diplomados tendem a desenvolver percursos em que o desemprego é mais raro e a obtenção de emprego mais rápida, ao mesmo tempo que se manifestam bastante satisfeitos com a sua situação e percurso profissionais. Como é evidente, estes resultados obtidos junto de diplomados das áreas da Engenharia, da Matemática e da Química, não podem ser generalizados a todos os diplomados de todas as áreas científicas do Ensino Superior. Por exemplo, no caso das licenciaturas destinadas à formação de professores, a média final é determinante para a colocação através do concurso nacional de docentes do sistema educativo público. A observação deste conjunto de dados empíricos referentes à 
articulação entre sucesso dos percursos académicos e características dos percursos profi ssionais revela a complexidade dessas (des)articulações.

31 Retomando a caracterização da situação profissional dos inquiridos, interessa analisar a informação disponível sobre o vínculo contratual dos diplomados. No caso do estudo realizado em Lisboa assinala-se que o grupo dos assalariados é o mais numeroso, mas identificam-se no seu interior três situações distintas: trabalhadores ocasionais (5,3\%), trabalhadores com contrato a termo certo $(27,1 \%)$ e trabalhadores com contrato a tempo indeterminado (24\%). Em Aveiro a informação referente ao tipo de vínculo com a entidade patronal indica a seguinte distribuição: estagiários $(2,1 \%)$, contratados $(40,6 \%)$, contratados a prazo $(39,7 \%)$, trabalhadores independentes/recibos verdes $(4,7 \%)$, trabalhadores ocasionais $(0,5 \%)$ e outra situação $(12,4 \%)$. Em Beja os contratados "sem termo" perfazem $35,8 \%$, aqueles que estão "com termo certo/a prazo" $37,2 \%$, os que têm contratos de "prestação de serviços" $11,2 \%$, em "situações de trabalho pontuais e ocasionais" 0,5\%, como "estagiários" 6,2\% e 9,1\% noutra situação. No Algarve a informação referente à "estabilidade contratual" organiza-se da seguinte forma: "pertence aos quadros" (39,2\%), "contrato com renovação garantida" $(10,1 \%)$, "contrato a termo certo" (24,1\%), "recibo verde" (13,9\%), "estágio profissional" (5,1\%) e outra situação (7,6\%). Globalmente, constata-se então que as situações de precariedade sob diferentes formas (contratos a prazo, trabalhos ocasionais, prestação de serviços, entre outras) prevalecem como as que abrangem a maior parte dos inquiridos nestes quatro estudos.

\section{Opiniões dos inquiridos sobre a sua situação profissional numa perspectiva comparada}

No que respeita aos indicadores que incidem sobre a dimensão das apreciações e representações dos sujeitos, considerámos pertinente analisar, comparativamente, os dados que resultam das seguintes questões: "qual a adequação da formação inicial ao exercício das suas funções profissionais?" (Beja), "que relação existe entre a sua ocupação profissional actual e o curso que concluiu no Ensino Superior?" (Lisboa, Algarve, Aveiro). Ainda que as questões não estejam formuladas exactamente do mesmo modo, entendemos que contêm potencial de comparabilidade num domínio que nos parece muito relevante e que remete para as percepções dos sujeitos sobre a articulação entre Ensino Superior e mercado de trabalho.

No caso de Lisboa, $72 \%$ dos inquiridos consideram que a sua ocupação profissional está numa "área relacionada com o curso", 14\% que está numa "área próxima" e $14 \%$ numa "área diferente". No caso do Algarve, a área de actividade é considerada "directamente relacionada" por $58,4 \%$, "próxima" por $26,1 \%$ e "totalmente diferente" por $15,5 \%$. No caso de Beja, 70\% consideram a formação "adequada", 12,9\% "muito adequada", 15,2\% "inadequada" e 1,9\% "muito inadequada". Globalmente, são então notórios consensos alargados em torno da ideia de uma adequação/correspondência entre curso/formação e área de actividade profissional, sendo residuais os grupos que negam a existência dessa adequação/correspondência.

Ainda no domínio das apreciações e opiniões dos sujeitos relativamente à sua situação no momento da inquirição, é notório que, no que respeita aos graus de satisfação com a situação profissional actual, esta é considerada elevada entre os inquiridos em Aveiro (em 
média quatro numa escala de seis). No caso dos estudos de Lisboa e Algarve, este grau de satisfação é indagado a propósito de diversas vertentes:

- no caso do Algarve constata-se que os aspectos mais valorizados ${ }^{6}$ são, por ordem decrescente de satisfação, a "relação com os colegas"; reunindo sensivelmente o mesmo número de respostas temos o "interesse da actividade", a "utilidade social" e o "horário de trabalho" e, um pouco menos evidenciados (mas sempre acima de $60 \%$ das respostas), surgem a "autonomia de que se dispõe" e a "estabilidade"; os dois aspectos menos valorizados correspondem ao "nível de remuneração" (50\% de satisfação) e às "oportunidades de promoção" (45\% de satisfação). Tendo em conta os níveis elevados de satisfação com estes diversos aspectos, compreende-se que, quando interrogados sobre até que ponto o enquadramento profissional correspondeu às expectativas que os diplomados tinham, mais de metade $(56,6 \%)$ responda que "correspondeu" e mesmo que "excedeu" (14,2\%) ou "excedeu muito" (2\%).

- no caso da Universidade de Lisboa, constata-se que são igualmente mais valorizadas ${ }^{7}$ as opções de resposta: "relação com os colegas" (90,8\%), "utilidade social" (89,9\%), "interesse da actividade" (88,3\%), seguindo-se "autonomia de que se dispõe" $(79,1 \%)$ e "horário de trabalho" (78,4\%); ainda reunindo mais de metade dos inquiridos surgem "acesso à formação contínua" (62,6\%), "estabilidade" (52,4\%) e "nível de remuneração" (50,7\%); o aspecto menos valorizado é "oportunidades de promoção" (44,8\%).

Para além de sublinhar os graus de satisfação elevados manifestados pelos diplomados de Aveiro, Algarve e Lisboa relativamente à sua situação profi ssional actual, consideramos essencial destacar o consenso que decorre da análise comparativa dos resultados obtidos no Algarve e em Lisboa, pois os aspectos mais e menos valorizados são os mesmos, bem como a hierarquização de todos é quase exactamente a mesma. Sobre esta convergência podemos avançar uma hipótese interpretativa que sublinha que tal é, afinal, o resultado de um processo de socialização ocorrido no Ensino Superior que dá origem a um conjunto de atitudes e representações sobre a esfera profissional bastante semelhantes entre os diplomados deste nível de ensino em diversas instituições. Neste quadro, de entre os aspectos que mais satisfazem os diplomados no seu trabalho, destacam-se a relação com colegas, a utilidade social e o interesse da sua actividade; no extremo oposto os aspectos que geram mais insatisfação são a remuneração e as oportunidades de promoção.

Estas mesmas tendências são identificáveis noutras pesquisas, designadamente centradas em diplomados de Engenharia, Química e Matemática (Alves, M., 2007) e num estudo em que o "trabalho interessante" surge com forte relevância entre jovens advogados, sendo que alguns (em minoria) não recomendariam a profissão que têm pelo facto de a considerarem uma actividade desinteressante (Chaves, 2010).

\section{Notas conclusivas}

$39 \mathrm{Na}$ ausência de informação recolhida a nível nacional sobre inserção pro-fi ssional de diplomados do Ensino Superior, este artigo decorre da análise comparativa de quatro estudos realizados nos anos mais recentes que permitem retratar a situação de uma diversidade de áreas disciplinares em várias regiões do país. O confronto entre os resultados obtidos nesta análise comparativa e os resultados de diversos estudos produzidos numa dada instituição ou numa dada área de formação não origina constrastes significativos. Ou seja, do ponto de vista substantivo, as conclusões que se 
obtêm na análise comparativa apenas reforçam alguns aspectos que vêm sendo destacados pelos investigadores em diferentes instituições.

Em primeiro lugar, a grande maioria dos indivíduos encontra-se empregada, ainda que tal varie consoante a área disciplinar e o curso, sublinhando-se que a precaridade dos vínculos contratuais afecta um grande número de diplomados. Como sublinhámos num outro texto (Alves, M., 2010), à luz das pesquisas de doutoramento sobre inserção profi ssional de diplomados que vêm sendo concretizadas no nosso país, não é possível apoiar a ideia de que as situações de inserção profissional de graduados possam ser consideradas, globalmente, catastróficas. Porém, todas as pesquisas identificam dificuldades e dinâmicas de recomposição, quer nas experiências e trajectórias no quadro do Ensino Superior quer nas estratégias e valores referentes à inserção profissional.

41 Em segundo lugar, é notório que a maioria dos inquiridos afi rma existir uma adequação entre a formação académica e a actividade profi ssional desempenhada, o que significa que poucos são os que afirmam existirem descoincidências entre o curso que frequentaram no Ensino Superior e a profi ssão que ocupam. Adicionalmente, interessa sublinhar a existência de níveis elevados de satisfação dos diplomados com a sua situação profissional, bem como o modo como os mesmos são justificados pelos próprios, através da valorização de aspectos como a "utilidade" e o "interesse" do trabalho que desenvolvem e a qualidade da "relação com colegas". Estes elementos, os dois primeiros em particular, podem em nosso entender ser tributários de processos de socialização pro fi ssional transversais às instituições educativas de nível superior.

42 A identificação destas tendências gerais não dispensa, aliás exige, a pesquisa a nível das instituições e dos cursos, de modo a caracterizar, com maior profundidade e em particular, os casos em que a não-adequação entre o curso e a actividade profissional, a insatisfação com a situação profissional e o desemprego entre os diplomados apresentam valores mais elevados.

A um nível de análise macro, centrado no Ensino Superior na sua globalidade, a identifi cação destas tendências gerais também levanta novas interrogações, nomeadamente quanto ao papel do Ensino Superior na inserção profissional dos seus diplomados. Por um lado, interessa sublinhar que pouco pode ser feito nas instituições de Ensino Superior para facilitar a existência de (mais) oportunidades de emprego para diplomados e a existência de (melhores) condições de exercício do emprego. Por outro lado, embora os dados da análise comparativa não o revelem, sabemos que diversos estudos empíricos em Portugal e noutros países (Alves, 2007, Martins, Arroteia e Gonçalves, 2002; Knight e Yorke, 2004, entre muitos outros) têm evidenciado que as principais difi culdades identifi cadas pelos diplomados em fase de inserção profi ssional estão relacionadas com o desempenho e exercício da actividade profi ssional ou com a integração e interrelacionamento pessoal nas organizações de trabalho. Ora, neste domínio, muito pode ser feito para ajudar a minimizar a situação de "choque" que os diplomados genericamente identifi cam na transição para o mundo do trabalho e para favorecer uma mais rápida integração nas actividades e nas organizações de trabalho.

Não obstante, importa sublinhar, como referimos inicialmente, que qualquer que seja o papel de uma dada instituição de Ensino Superior na inserção profissional dos diplomados, o modo como as trajectórias se desenrolam depende também das dinâmicas do mercado de trabalho, das estratégias e opções dos próprios diplomados e do contexto 
societal, económico e político em que a regulação entre educação-trabalho-emprego se vai reconfi gurando continuamente.

Por fim, em jeito de balanço, gostaríamos de destacar que se revelaram evidentes as difi culdades, que já antevíamos, de comparar os estudos existentes. Essas dificuldades decorrem das diferentes opções seguidas na constituição das amostras, mas sobretudo na variabilidade de perguntas e opções de resposta dos instrumentos de recolha de dados, as quais remetem para uma multiplicidade de indicadores cuja comparação nem sempre é possível. A este propósito emerge, aliás, a interrogação: até que ponto é correcto este tipo de análise comparativa e que aprofundamento do conhecimento sobre as transições permite?

\section{BIBLIOGRAFIA}

ALMEIDA, António José, VAZ, Isabel, MARQUES, Maria Amélia e DOMINGUINHO, Pedro (2007), Inserção Profissional dos Licenciados pela ESCE: Relatório do inquérito realizado em 2006/07, Escola Superior Ciências Empresariais - Instituto Politécnico Setúbal (policopiado).

ALVES, Mariana Gaio (2005), “The Entry into Working Life of Higher Education Graduates: An Educational Perspective", European Journal Vocational Training, number 34, January-April 2005/I, pp. 28-39.

ALVES, Mariana Gaio (2007), A Inserção Profissional de Diplomados de Ensino Superior numa Perspectiva Educativa: O Caso da Faculdade de Ciências e Tecnologia, Lisboa, edição FCT/ FCG.

ALVES, Mariana Gaio (2008), “Contributos para pensar a regulação entre educação, trabalho e emprego", Universidade e Formação ao Longo da Vida, Oeiras, edições Celta.

ALVES, Mariana Gaio (2010), “A inserção profissional de graduados em Portugal: notas sobre um campo de investigação em construção" in Ana Paula Marques e Mariana Gaio (Orgs.), Inserção Profi ssional de Graduados em Portugal: (Re)configurações teóricas e empíricas, V.N. Famalicão, Edições Húmus.

ALVES, Natália (2005), Trajectórias Académicas e de Inserção Profissional dos Licenciados (1999-2003), Lisboa, Edição Universidade de Lisboa.

ALVES, Natália (2008), Juventudes e Inserção Profissional, Lisboa, Educa. C

HAVES, Miguel e MORAIS, César (2008), Relatório sobre o Percurso dos Licenciados da FCSH/ UNL que Conluíram os Cursos no Ano de 2002, Lisboa, FCSH/UNL (policopiado).

CHAVES, Miguel (2010), Confrontos com o Trabalho entre Jovens Advogados: As novas confi gurações da inserção profissional, Lisboa: Edições Imprensa Ciências Sociais.

DUBOIS, Pierre (2004), Synthèse des enquêtes 2001-2004) sur les DEA et les docteurs (1999-2002) de l'ENPC et de le l'UMLV, Université de Marne-la-Vallée.

GERALDES, Maria e SANTOS, Paulo (Orgs.) (2004), A Inserção Profissional dos Jovens Diplomados no Algarve entre 1999-2001, Faro, Fundação da Juventude-Delegação do Algarve. 
GONÇALVES, Carlos e MENESES, Isabel (2010), Resultados do Inquérito aos Diplomados da Universidade do Porto 2007/08, acesso em Setembro 2010, http://sigarra.up.pt/up/ conteudos_geral.conteudos_ver? pct_pag_id=1001785\&pct_parametros=p_pagina=1001785\&pct_disciplina=\&pct_grupo=1441\&pct_grupo=2661\#2661.

GONÇALVES, Manuela (2007), Educação, Trabalho e Familia: Trajectórias de diplomados universitários, Tese de Doutoramento, Universidade de Aveiro.

GONÇALVES, Albertino (2001), As Asas do Diploma: A inserção profissional dos licenciados pela Universidade do Minho, Braga, Edição Universidade do Minho.

MARQUES, Ana Paula (2006), Entre o Diploma e o Emprego: A inserção profissional de jovens engenheiros, Porto, Edições Afrontamento.

MARTINS, António Maria, ARROTEIA, Jorge Carvalho e GONÇALVES, Maria Manuela (2002), Sistemas de (Des)emprego: Trajectórias de inserção, Aveiro, Edição Universidade de Aveiro.

SAÚDE, Sandra (2005), Percursos de Inserção Profissional dos Diplomados do Ensino Superior Politécnico, Beja, Edição Instituto Politécnico de Beja.

SEBASTIÃO, João (org.), SILVA, Francisco, VAL, Helena; TEIXEIRA, Leonor e JESUS, Sónia (2009), Formação, Investigação e Inserção Profissional: Uma avaliação do trabalho desenvolvido pela ESES (Escola Superior de Educação de Santarém), Chamusca, Edições Cosmos.

STIWNE, Elinor e ALVES, Mariana Gaio (2010), "Higher Education and Employability of Graduates: Will Bologna Make a Difference?”, European Educational Research Journal, volume 9, number 1, pp. 32-44.

TEIXEIRA, Leonor (2009), Trajectórias e Cenários de Inserção Profissional de Diplomados em Educação Social do Ensino Superior Politécnico: Pontes e vazios na relação entre percursos de formação e percursos de inserção profissional, Tese de Mestrado, FCT/UNL (policopiado).

\section{ANEXOS}

Quadro 1 - Caracterização geral dos estudos : análise comparativa 


\begin{tabular}{|c|c|c|c|c|}
\hline $\begin{array}{l}\text { Estudo// } \\
\text { Informação }\end{array}$ & (a) U. Lisboa & (b) P. Beja & (c) U. Algarve & (d) U. Aveiro \\
\hline $\begin{array}{c}\text { Ano de } \\
\text { publicacăào }\end{array}$ & 2005 & 2005 & 2004 & 2002 \\
\hline & 2005 & 2004 & 2003 & 2001 \\
\hline $\begin{array}{l}\text { Ano de } \\
\text { conclusão de } \\
\text { cursos dos } \\
\text { inquiridos }\end{array}$ & 1999-2003 & $2000-2003$ & 1999-2001 & 1995/96-1999/00 \\
\hline $\begin{array}{l}\text { Metodologia do } \\
\text { estudo empírico } \\
\text { (em fases) }\end{array}$ & $\begin{array}{l}\text { Única fase: } \\
\text { Quescionário } \\
\text { (semelhante } \\
\text { ao que } \\
\text { haviam } \\
\text { aplicado em } \\
\text { 2000) }\end{array}$ & $\begin{array}{c}\text { 1.: Entrevistas a infor- } \\
\text { mantes privilegiados; } \\
\text { 2.:": Questionário a todos } \\
\text { os diplomados; } \\
\text { 3..;: Questionário a grupo } \\
\text { restrito de diplomados }\end{array}$ & $\begin{array}{l}1{ }^{a}: \text { Questioná- } \\
\text { rio a diploma- } \\
\text { dos; } \\
\text { 2.a : Entrevistas } \\
\text { sob a forma } \\
\text { de histórias de } \\
\text { vida }\end{array}$ & $\begin{array}{l}\text { Unica fase: } \\
\text { Questionário } \\
\text { (semelhante } \\
\text { ao que haviam } \\
\text { aplicado cm } \\
\text { 1997) }\end{array}$ \\
\hline $\begin{array}{l}\text { Universo/ } \\
\text { amostra }\end{array}$ & $\begin{array}{l}\text { Universo: } \\
\text { diplomados } \\
\text { da U. Lisboa } \\
\text { entre 1999 } \\
\text { e 2003 } \\
\text { (N=8107); } \\
\text { Amostra } \\
\text { (N=2216) }\end{array}$ & 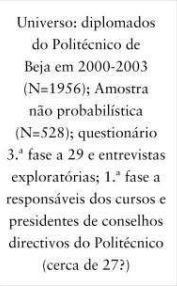 & $\begin{array}{c}\text { Universo: } \\
\text { diplomados } \\
\text { nas instituicốes } \\
\text { algarvias em } \\
\text { 1999-2001; } \\
\text { Amostra } \\
\text { aleatória } \\
\text { estratificada } \\
\text { (N=426) e dez } \\
\text { entrevistas } \\
\text { "historias de } \\
\text { vida" }\end{array}$ & $\begin{array}{c}\text { Universo: } \\
\text { diplomados na } \\
\text { U. Aveiro entre } \\
95 / 96 \mathrm{e} 99 / 00 \\
\text { (N=3372); } \\
\text { Amostra } \\
(\mathrm{N}=1191), \\
\text { existindo } \\
\text { algumas } \\
\text { subamostras } \\
\text { de cursolárea } \\
\text { sem significado } \\
\text { estatístico }\end{array}$ \\
\hline $\begin{array}{l}\text { Enquadramento } \\
\text { institucional/ } \\
\text { equipa do estudo }\end{array}$ & $\begin{array}{l}\text { Docente da } \\
\text { instituição } \\
\text { no quadro de } \\
\text { iniciativa da } \\
\text { Reitoria }\end{array}$ & $\begin{array}{l}\text { Equipa de docentes da } \\
\text { instituição no quadro de } \\
\text { projecto financiado pelo } \\
\text { POEFDS' }\end{array}$ & $\begin{array}{c}\text { Coordenaçāo } \\
\text { cientifica de } \\
\text { docente, equipa } \\
\text { da Fundação } \\
\text { da Juventude } \\
\text { no quadro } \\
\text { de projecto } \\
\text { financiado pelo } \\
\text { POEFDS }\end{array}$ & $\begin{array}{c}\text { Equipa de } \\
\text { docentes da } \\
\text { instituição no } \\
\text { quadro de uma } \\
\text { das unidades de } \\
\text { investigacạão da } \\
\text { U. Aveiro }\end{array}$ \\
\hline $\begin{array}{c}\text { Graus dos } \\
\text { diplomados } \\
\text { inquiridos }\end{array}$ & $\begin{array}{c}\text { Só } \\
\text { Licenciados }\end{array}$ & Licenciados e Bacharéis & $\begin{array}{c}\text { Licenciados } \\
(2 / 3) \\
\text { Bacharéis (1/3) }\end{array}$ & $\begin{array}{c}\text { Maioria } \\
\text { Licenciados } \\
\text { (+ } 6 \text { Bacharéis) }\end{array}$ \\
\hline
\end{tabular}

' POEFDS - Programa Operacional de Emprego, Formação e Desenvolvimento Social.

Quadro 2 - Estrutura dos capítulos de apresentação de dados dos questionários: análise comparativa

\begin{tabular}{|c|c|}
\hline Estudo & Estrutura capítulos \\
\hline $\begin{array}{c}\text { (a) } \\
\text { U. Lisboa }\end{array}$ & $\begin{array}{l}1 \text { - Caracterização sociográfica de diplomados da Universidade de Lisboa; } 2 \text { - Estatuto } \\
\text { ocupacional em Outubro de 2004; } 3 \text { - Trajectórias escolares e opinião sobre o curso; } 4 \\
\text { - Inserção na vida activa; } 5 \text { - Trajectórias de inserção; } 6 \text { - Trajectórias profissionais dos } \\
\text { trabalhadores-estudantes }\end{array}$ \\
\hline (b) P. Beja & $\begin{array}{l}1 \text { - Perfil sociodemográfico e origens sociais; } 2 \text { - Trajectória escolar: escolha do curso; } \\
3 \text { - Percursos de inserção profissional; } 4 \text { - Situação profissional; } 5 \text { - Relação entre curso } \\
\text { e exercício profissional }\end{array}$ \\
\hline $\begin{array}{c}(\mathrm{c}) \\
\text { U. Algarve }\end{array}$ & $\begin{array}{l}1 \text { - Diplomados no Algarve (1999/2001) - áreas de formação e auto-avaliação da } \\
\text { trajectória académica; } 2 \text { - Trajectórias profissionais e atitudes face ao trabalho; } 3 \text { - A } \\
\text { empregabilidade dos diplomados - situação actual; } 4 \text { - Atitudes e práticas perante a } \\
\text { sociedade; } 5 \text { - Perfil social dos diplomados }\end{array}$ \\
\hline $\begin{array}{c}\text { (d) } \\
\text { U. Aveiro }\end{array}$ & $\begin{array}{l}1 \text { - Caracterização sociodemográfica e escolar; } 2 \text { - Percurso formativo após o diploma; } \\
3 \text { - Estudantes-trabalhadores: situação no último ano do curso e trajectória profissional; } \\
4 \text { - Situação dos diplomados em Maio de } 2001 ; 5 \text { - Transição para a vida activa e } \\
\text { trajectórias profissionais de diplomados; } 6 \text { - Os diplomados e a Universidade de Aveiro; } \\
7 \text { - Representações da vida social e profissional dos diplomados e perspectivas futuras }\end{array}$ \\
\hline
\end{tabular}

Quadro 3 - Indicadores da dimensão de análise "situação profissional actual": análise comparativa 


\begin{tabular}{|c|c|}
\hline $\begin{array}{l}(\mathrm{a}) \mathrm{U} . \\
\text { Lisboa }\end{array}$ & $\begin{array}{l}\text { Estatuto ocupacional dos diplomados (desempregado, estudantes, estágio, } \\
\text { assalariados, patrões e trabalhadores independentes). Nível de remuneração (inferior } \\
\text { a } 300 \text { euros, } 301 \text { a } 500,501 \text { a } 1000,1001 \text { a } 1500 \text {, superior a 1500). Profi ssão dos } \\
\text { diplomados. Grau de satisfação com os vários aspectos relacionados com o emprego } \\
\text { (estabilidade, nível de remuneração, oportunidades de promoção, autonomia de que } \\
\text { dispõe, interesse da actividade, relação com os colegas, utilidade social, horário de } \\
\text { trabalho, acesso à formação contínua). Relação horário/remuneração (trabalhar mais } \\
\text { horas e ganhar mais dinheiro, trabalhar o mesmo número de horas e ganhar o mesmo } \\
\text { dinheiro, trabalhar menos horas e ganhar menos dinheiro). Avaliação face à ocupação } \\
\text { (só faço aquilo que tenho obrigação de fazer, trabalho bastante mas não deixo que } \\
\text { isso interfira com o resto da minha vida, faço questão de trabalhar o melhor possível } \\
\text { mesmo que isso interfi ra na minha vida). }\end{array}$ \\
\hline & $\begin{array}{l}\text { Situação profi ssional actual (empregado, desempregado, outra). Tipo de contrato de } \\
\text { trabalho (sem termo, a termo certo, prestação de serviços, trabalho pontual e } \\
\text { ocasional, estágio, outro). Exerce funções profi ssionais na área do curso (sim/não). } \\
\text { Adequação da formação ao exercício de funções profi ssionais na área. }\end{array}$ \\
\hline $\begin{array}{l}\text { (c) } \\
\text { U. } \\
\text { Algarve }\end{array}$ & $\begin{array}{l}\text { Situação actual perante o emprego (trabalha; não trabalha, mas não procura } \\
\text { emprego; procura emprego; outra). Modalidade de emprego (a tempo inteiro, a } \\
\text { tempo parcial). Actividade da empresa (ramo de actividade económica...). Tipo de } \\
\text { empresa ou organização (privada até } 10 \text { empregados, privada entre } 11 \text { e } 100 \text { emprega- } \\
\text { dos, privada com mais de } 100 \text { empregados, pública ou mista, administração pública, } \\
\text { por conta própria sem empregados, por conta própria com empregados, outra). } \\
\text { Estabilidade contratual (pertence aos quadros, contrato com renovação garantida, } \\
\text { contrato a } \\
\text { termo certo, recibo verde, estágio profi ssional, outro). } \\
\text { Relação entre a ocupação e o curso (directamente relacionada com o curso, área de } \\
\text { actividade } \\
\text { próxima, área de actividade totalmente diferente). } \\
\text { Rendimento líquido mensal (menos de } 250 \text { euros, entre } 250 \text { e } 500 \text {, entre } 501 \text { e } 1000 \text {, } \\
\text { entre } \\
\text { 1001 e 1500, mais de 1500). } \\
\text { Grau de satisfação quanto ao enquadramento profi ssional (em quatro graus } \\
\text { relativamente a } \\
\text { horário de trabalho, utilidade social, relação com os colegas, interesse da actividade, } \\
\text { autonomia } \\
\text { de que dispõe, oportunidades de promoção, nível de remuneração, estabilidade). } \\
\text { Tipo de adequação do enquadramento profi ssional às expectativas (muito aquém, } \\
\text { aquém, correspondeu, } \\
\text { excedeu, excedeu em muito). }\end{array}$ \\
\hline
\end{tabular}


Situação dos diplomados (estudante a tempo inteiro com bolsa, estudante a tempo inteiro sem

bolsa, estudante trabalhador, empregado, desempregado à procura de emprego, inactivo - não

procura emprego, estagiário com remuneração, estagiário sem remuneração, bolseiro de investigação,

outra situação).

Profi ssão dos diplomados (funções dirigentes, profi ssões intelectuais e científi cas, professor do

Ensino Superior universitário, professor do Ensino Superior politécnico, professor do 2. ${ }^{\circ}$ e 3.9

ciclos e do ensino secundário, professor do $1 .^{\circ}$ ciclo e educador de infância, profi ssões técnicas

intermédias, empregados administrativos, forças armadas, outra).

Ramo de actividade económica.

Organismo a que estão ligados os diplomados (empresa com capital privado, empresa com capital

familiar, empresa com capital público, autarquia local, universidade de Aveiro, Ministério

da Educação, organismo de outro ministério, outra).

Dimensão das empresas a que estão ligados os diplomados (1 a 4, 5 a 9, 10 a 49, 50 a 199 ,

(d) U. 200 a $499,=$ ou +500$)$.

Aveiro Local de desempenho das actividades profi ssionais (distrito e concelhos no caso do distrito de

Aveiro).

Situação na profi ssão (por conta própria-empresário, por conta própria-trabalhador independente,

por conta de outrem-assalariado, por conta própria e conta de outrem, trabalhador

familiar não remunerado, outra situação).

Tipo de jornada de trabalho (tempo inteiro, tempo parcial.)

Tipo de vínculo (estagiário, contratado, contratado a prazo, trabalhador indepndente com

recibos verdes, trabalho ocasional, outra).

Rendimento mensal líquido em contos (até 100, entre 101 e 150, entre 151 e 250, entre $251 \mathrm{e}$

350 , entre 451 e 550 , mais de 550).

Apreciação da situação social e profi ssional (satisfação com situação face ao emprego, articulação

entre diploma académico realizado e proventos recebidos, reconhecimento social por ser licenciado,

reconhecimento social por ser licenciados pela Universidade de Aveiro, situação geral melhorou relativamente aos pais, situação no emprgeo vai melhorar com estabilidade, situação

no emprego vai melhorar materialmente, situação no emprego vai melhorar em estatuto). 
No caso deste estudo há um conjunto de perguntas sobre a actividade profissional secundária que optamos por não considerar, pois são respondidas por cerca de um terço dos inquiridos mas correspondem ao mesmo tipo de indicadores.

\section{NOTAS}

1. Veja-se o trabalho de Gonçalves, (2007), na Universidade de Aveiro ou de Alves, (2007), na Universidade de Lisboa.

2. A lei n. ${ }^{3}$ 38/2007 de 16 de Agosto estabelece que uma das dimensões da auto-avalição das instituições de Ensino Superior é a monitorização da trajectória de empregabilidade dos seus diplomados, sublinhando que um dos critérios de qualidade do Ensino Superior é a inserção dos seus diplomados no mercado de trabalho.

3. Designadamente, identificámos a existência de estudos similares na Universidade de Coimbra e no Instituto Superior Técnico, mas, apesar de contactos vários, não nos foi facultado o acesso aos respectivos relatórios. Um estudo realizado na Universidade do Minho realizado em 1997/98 não foi também considerado na análise comparativa pelo facto de o trabalho empírico ser anterior ao ano de 2001 (Gonçalves, 2001).

4. São considerados neste estudo os diplomados da Universidade do Algarve (única instituição de Ensino Superior público na região), dos Institutos Superiores de Matemáticas e Gestão e de Humanidades e Tecnologias (Grupo Lusófona), do Insituto Superior de Dom Afonso III e da Escola Superior de Saúde Jean Piaget.

5. O valor apontado para o Algarve deve ser considerado com alguma cautela, uma vez que engloba aqueles que "não trabalham e não procuram emprego" $(2,3 \%)$ e aqueles que "procuram emprego" (12,2\%). Mas não poderão estes últimos estar a trabalhar? No caso dos outros estudos a opção de resposta era "desempregado", ainda que pudesse desagregar-se em "desempregado à procura do primeiro emprego" ou "desempregado à procura de novo emprego" ou "desempregado que não procura emprego".

6. Consideramos mais valorizados os aspectos em que mais indivíduos se declaram "muito satisfeitos" e "satisfeitos" e que no conjunto destas duas opções de resposta abrangem mais de $60 \%$ dos inquiridos.

7. Consideramos, de igual modo, mais valorizados os aspectos em que mais indivíduos se declaram "completamente satisfeitos" e "satisfeitos" e todos os valores apresentados resultam da soma destas duas opções de resposta para cada um dos aspectos considerados.

\section{RESUMOS}

Este artigo resulta de um exercício de análise comparativa de estudos sobre inserção profissional de diplomados do Ensino Superior. Constatando-se a ausência de informação estatística detalhada a nível nacional sobre estas matérias, foi nossa intenção procurar sistematizar informação empírica disponível em resultado de estudos extensivos que vêm sendo concretizados ao longo da última década em diversas instituições de Ensino Superior. O exercício de análise comparativa revelou-se uma tarefa complexa devido à multiplicidade de procedimentos, critérios de amostragem e instrumentos de recolha de dados escolhidos nos vários estudos, conduzindonos à interrogação sobre se será pertinente continuá-lo. Do ponto de vista dos dados substantivos, reúnem-se neste artigo elementos que permitem caracterizar as situações profi ssionais dos diplomados no momento da inquirição, tanto no que respeita às características das trajectórias protagonizadas quanto no plano das opiniões sobre as mesmas.

Os resultados reforçam algumas conclusões que vêm sendo apontadas em vários trabalhos de 
investigação que têm como referência uma determinada instituição e/ou área de formação especí fica. Designadamente, torna-se possível uma caracterização genérica das dinâmicas de "trabalho" e "não-trabalho" de um grupo específi co que são os diplomados de Ensino Superior. Por um lado, é evidente o contraste dos resultados obtidos com o retrato traçado nos discursos correntes e mediáticos, que enfatizam as dificuldades deste grupo populacional no mercado de trabalho. Não obstante, acumulam-se indícios de que as difi culdades de inserção profissional têm vindo a aumentar ao longo dos anos e que, para além dos casos de desemprego, as situações de precariedade do vínculo contratual são muito significativas. No plano das opiniões dos inquiridos, identificam-se tendências gerais de satisfação relativamente à situação profi ssional e de afirmação da existência de correspondência e/ou adequação entre formação académica e actividade profi ssional desempenhada.

This article is the result of a comparative analysis of studies focusing the transition to working life of higher education graduates. We acknowledge the absence of detailed statistical data about these processes in Portugal. Being so, we produced a comparative analysis of empirical data available within surveys that have been completed in the last ten years in different Portuguese higher education institutions.

Cet article résulte d'une analyse comparative des études sur l'insertion professionnelle des diplômés de l'enseignement supérieur. On a vérifi é l'absence d'informations statistiques détaillées au niveau national sur ces questions. Par conséquent, notre intention était d'obtenir des informations systématiques à travers les résultats empiriques des études qui ont été réalisés au cours de la dernière décennie dans plusieurs établissements de l'enseignement supérieur au Portugal.

ÍNDICE

Mots-clés: enseignement supérieur, insertion des diplômés, analyse comparative

Palavras-chave: ensino Superior, inserção profissional de licenciados, análise comparativa

Keywords: Higher Education, professional, insertion of graduates, comparative analysis

\section{AUTOR}

\section{MARIANA GAIO ALVES}

Faculdade de Ciências e Tecnologia, Universidade Nova de Lisboa

mga@fct.unl.pt 